\title{
First Evidence that Sika Deer (Cervus nippon) Velvet Antler Extract Suppresses Migration of Human Prostate Cancer Cells
}

\author{
YuJiao Tang ${ }^{1,2,3}$, Byong-Tae Jeon ${ }^{1,2}$, Yanmei Wang ${ }^{3}$, Eun-Ju Choi ${ }^{4}$, Yon-Suk Kim ${ }^{5}$, Jin-Woo Hwang ${ }^{5}$, \\ Pyo-Jam Park ${ }^{2,5}$, Sang Ho Moon ${ }^{1,2, *}$, and Eun-Kyung Kim ${ }^{1,2, *}$ \\ ${ }^{1}$ Division of Food Bio Science, College of Biomedical and Health Sciences, \\ Konkuk University, Chungju 380-701, Korea \\ ${ }^{2}$ Korea Nokyong Research Center, Konkuk University, Chungju 380-701, Korea \\ ${ }^{3}$ Jilin Sino-Rok Institute of Animal Science, Changchun 130-600, China \\ ${ }^{4}$ Division of Sport Science, College of Biomedical and Health Sciences, Konkuk University, Chungiu 380-701, Korea \\ ${ }^{5}$ Department of Biotechnology, Konkuk University, Chungju 380-701, Korea
}

\begin{abstract}
Deer velvet antler (DVA) is one of the most popular medicines in China. Numerous studies have demonstrated that velvet antler possess biological effects. However, data regarding its anti-migration activity on prostate cancer is scarce. In this study, we investigated the inhibitory effect of top DVA (T-DVA) on the expression of prostate-specific antigen (PSA) and migration-related genes in the human prostate cancer cell, LNCaP. The T-DVA down-regulated the expression of PSA. In addition, the Radius ${ }^{\mathrm{TM}}$ assay revealed that T-DVA inhibited the migration behavior of prostate cancer cells. Furthermore, the expression of matrix metalloproteinase (MMP)- 9 and vascular endothelial growth factor (VEGF) was also decreased with T-DVA. On the contrary, T-DVA increased the tissue inhibition of metalloproteinase (TIMP)-1 and (TIMP)-2. Taken together, our findings indicate that the T-DVA possesses anti-migration activity on prostate cancer cells. This is the first study of DVA to report the anti-migration activity on prostate cancer.
\end{abstract}

Keywords: Deer velvet antler, prostate cancer, PSA, migration

Received June 2, 2015; Revised July 20, 2015; Accepted July 20, 2015

\section{Introduction}

Sika deer velvet antler (DVA) is one of the most popular traditional medicines in China and Korea. Velvet antler has been recorded in Chinese medical classics, such as ShenNong Ben Cao Jing 2000 years ago. It is believed to nourish the Yin, possess body strengthening, immunomodulatory and anti-aging effects, tonify the kidney, invigorate the spleen, strengthen bones and muscles, and promote blood flow (Wu et al., 2013). In Korea, it is generally referred to as "Nokyong" and is one of the most popular Korean traditional medicines. The benefits of DVA are supported by extensive in vivo and in vitro studies

\footnotetext{
*Corresponding authors: Sang Ho Moon, Division of Food Bio Science, College of Biomedical and Health Sciences, Konkuk University, Chungju, 380-701, Korea. Tel: +82-43-840-3527, Fax: +82-43-840-3526, E-mail: moon0204@kku.ac.kr;

Eun-Kyung Kim, Division of Food Bio Science, College of Biomedical and Health Sciences, Konkuk University, Chungju, 380701, Korea. Tel: +82-43-840-3581, Fax: +82-43-840-3526, Email: eunkyungkim@kku.ac.kr
}

(Sunwoo et al., 1997). Numerous studies have also demonstrated that velvet antler possess anti-cancer, antiinflammatory, anti-stress, and anti-aging (Takikawa et al., 1972; Wang et al., 1988; Zhang et al., 1992). Meanwhile, it is generally believed that the use of velvet antler should be avoided in men with hormone-sensitive diseases, such as prostate cancer. To the best of our knowledge, there is no scientific evidence of the bioactivity and safety of velvet antler for managing diseases in men.

Prostate cancer is one of the most common noncutaneous cancers in men and the second leading cause of cancer-related deaths in men (Ferlay et al., 2013). With its increased incidence in recent years, the mortality from prostate cancer has increased (Tormey, 2014). In addition, there has been a recent trend in Asia toward an increasing incidence of prostate cancer, with a more rapid increase than that reported from high-rich countries. The presence of prostate cancer is confirmed on the detection of PSA, and the basis of symptoms, physical examination result, or biopsy findings. PSA is one of the most important biomarkers currently used to check for signs of the pres-

(9)This is an open access article distributed under the terms of the Creative Commons Attribution Non-Commercial License (http://creativecommons.org/licences/ by-nc/4.0) which permits unrestricted non-commercial use, distribution, and reproduction in any medium, provided the original work is properly cited. 
ence of prostate cancer. In addition, MMPs are a trigger mechanism in tumor migration, and contribute to tumor cells into the blood vessels and distant metastasis (McCawley and Matrisian, 2001; Morgan et al., 2010; Nishimura et al., 2008). Hence, MMPs considered potential markers of migration and metastasis of malignant tumor cells. Meanwhile, there are natural inhibitors of MMPs, a group of peptidases involved in degradation of the extracellular matrix, that is, TIMPs. They are the glycoproteins, and thought to be thought to be a metastasis suppressor. Moreover, VEGF is considered to be the main factor that promotes angiogenesis of prostate cancer, is also related to metastasis of prostate cancer (Cho et al., 2001).

Numerous studies have demonstrated that the progression of cancer can be retarded by using plants and the chemical substances (Mehta and Pezzuto, 2002). However, little is known about inhibition of prostate cancer cells by compound from animal sources such as velvet antler.

Therefore, in the present study, we investigated the effects of DVA on prostate cancer cells.

\section{Materials and Methods}

\section{Materials}

Seven sika DVAs were harvested and collected about $50 \mathrm{~d}$ after casting at the same farm (Fanrong farm, China). DVAs were lyophilized, divided into three sections; TDVA, M-DVA, and B-DVA. $10 \mathrm{~g}$ of each section were put into $100 \mathrm{~mL}$ of $70 \%$ ethanol. They were subjected to extraction $70 \%$ ethanol solution for $2 \mathrm{~h}$ and repeated three times. Then DVA extracts were filtered $(0.25 \mu \mathrm{m})$ and lyophilized (yield: top, 3.87\%; middle, 3.61\%; base, 2.66\%) in a freeze dryer for $5 \mathrm{~d}$. LNCaP, androgen-dependent human prostate cancer cells were obtained from Korean Cell Line Bank (Korea; KCLB numbers: 21740). DHT (dihydrotestosterone) was purchased from Sigma (USA). RPMI 1640 media for the cells and TRIzol reagent for RNA extraction were received from Invitrogen (USA). Antibodies for primary antibodies and the peroxidaseconjugated secondary antibodies were purchased from Santa Cruz Biotechnology Inc. (USA).

\section{DPPH radical scavenging activity}

Antioxidant activity plays a crucial role in anti-cancer (Li et al., 2007; Valko et al., 2006; Waris and Ahsan, 2006). Therefore, to select one of segments from 3 segments of DVA, DPPH radical scavenging activity of 3 segments were measured according to a slightly modified method of Blois (1958). DPPH solution $\left(1.5 \times 10^{-4} \mathrm{M}, 100 \mu \mathrm{L}\right)$ was mixed with or without DVA $(100 \mu \mathrm{L})$, after which the mixture was incubated at room temperature for $30 \mathrm{~min}$. After standing for $30 \mathrm{~min}$, absorbance was recorded at $540 \mathrm{~nm}$ by microplate reader and the percentage of scavenging activity was calculated using the following equation:

$$
\text { Inhibition }(\%)=\left(\mathrm{A}_{\text {control }}-\mathrm{A}_{\text {sample }}\right) / \mathrm{A}_{\text {control }} \times 100
$$

Where $\mathrm{A}_{\text {control }}$ is absorbance of reaction mixture without sample and $\mathrm{A}_{\text {sample }}$ is absorbance of reaction mixture with sample at $540 \mathrm{~nm}$. In addition, the activity was also calculated was as mmol trolox equivalent at $1,000 \mu \mathrm{g} / \mathrm{mL}$.

\section{Cell culture}

The human prostate cancer cell line, LNCaP cells were cultured in RPMI 1640 media, supplemented with $10 \%$ FBS, $1 \%$ penicillin/streptomycin in a $5 \% \mathrm{CO}_{2}$ atmosphere at $37^{\circ} \mathrm{C}$. The cells were seeded at a density of $5 \times 10^{5}$ cells in a 6-well culture plate. After $24 \mathrm{~h}$, the cells were treated with 125 to $1,000 \mu \mathrm{g} / \mathrm{mL}$ of T-DVA extract in media for $24 \mathrm{~h}$, and then harvested.

\section{Gap closure migration assay}

We performed the migration assay using the Radius ${ }^{\mathrm{TM}}$ 24-well from Cell Biolabs, Inc (USA). For the analysis, slowly added $500 \mu \mathrm{L}$ of Radius ${ }^{\mathrm{TM}}$ gel pretreatment solution to each well by carefully pipetting down the wall of the well, and then covered the plate and incubated at room temperature for $20 \mathrm{~min}$. Carefully aspirated the Radius ${ }^{\mathrm{TM}}$ gel pretreatment solution from the wells, and added 500 $\mu \mathrm{L}$ of Radius ${ }^{\mathrm{TM}}$ wash solution to each well. Harvested and resuspended cells in culture medium at $0.2 \times 10^{6} \mathrm{cell} /$ $\mathrm{mL}$. Carefully aspirated the Radius ${ }^{\mathrm{TM}}$ wash solution from the wells, and added $500 \mu \mathrm{L}$ of the cell suspension to each well by carefully pipetting down the wall of the well. Transfered the plate to a cell culture incubator for $24 \mathrm{~h}$ to allow firm attachment. After $24 \mathrm{~h}$, aspirated the media from each well, and washed 3 times with $0.5 \mathrm{~mL}$ of fresh media. Prepared sufficient $1 \mathrm{X}$ Radius ${ }^{\mathrm{TM}}$ gel removal solution for all wells by diluting the stock 1:100 in culture media. Aspirated the media from the wells and added 0.5 $\mathrm{mL}$ of $1 \mathrm{X}$ Radius ${ }^{\mathrm{TM}}$ gel removal solution from each well and washed 3 times with $0.5 \mathrm{~mL}$ of fresh media. After the final washing was complete, added $1 \mathrm{~mL}$ of complete medium with T-DVA extract (125 to $1,000 \mu \mathrm{g} / \mathrm{mL}$ ) to each well, and take a photo on $0,8,12,24 \mathrm{~h}$, respectively. To compare the differences in migratory gap, images were captured at the same size, and gap closure was determined 
after the indicated times $(0,8,12$, and $24 \mathrm{~h})$ using Cell Profiler $^{\mathrm{TM}}$ software (Broad Institute, USA).

\section{RNA isolation and mRNA expression analysis}

For the RT-PCR, the total cellular RNA was isolated from cells using TRIzol according to the manufacturer's protocol. The first-strand complementary DNA (cDNA) was synthesized using Superscript II reverse transcriptase (Invitrogen, USA). PCR was previously described with exception of primer sets of following primers PSA (s 5'AGC CCC AAG CTT ACC ACC-3'; as 5'-GCT GAC CTG AAA TAC CTG-3'), MMP-9 (s 5'-CGA CGT CTT CCA GTA CCG AG-3'; as 5'-GTT GGT CCC AGT GGG GAT TT-3'), TIMP-1 (s 5'-CAA GAT GAC CAA GAT GTA TAA AGG-3'; as 5'-AAC AGT GTA GGT CTT GGT GAA G-3'), TIMP-2 (s 5'-CAG CTT TGC TTT ATC CGG GC3'; as 5'-ATG CTT AGC TGG CGT CAC AT-3'), and VEGF (s 5'-GGG GCA GAA TCA TCA CGA AG-3'; as 5'-TTT CTC CGC TCTGAG CAA GG-3'). GAPDH (s 5'CCA TGG GGA AGG TGA AGG TC-3'; as 5'-AAA TGA GCC CCA GCC TTC TC-3') was used for internal control. The conditions for RT-PCR were similar ones that have been previously described.

\section{Western blot analysis}

Cell extracts were prepared by the detergent lysis procedure as described elsewhere (Kim et al., 2009b). Samples of protein $(40 \mu \mathrm{g})$ were electrophoresed using Novex 4-12\% Bis-Tris gel (Life Technolgies, USA), and then transferred to nitrocellulose membranes for $7 \mathrm{~min}$ in the iBlot dry blotting system (Life Technolgies, USA). Immunodetection was done using an enhanced chemiluminescence detection kit (Amersham Pharmacia, USA).

\section{Statistical analysis}

The experiments shown are, in fact, summaries of the data sourced from at least three experiments. All of data are presented using the mean \pm SE. Statistical analyses were performed using SAS statistical software (SAS Institute, USA). Treatment effects were analyzed using one-way analysis of variance, followed by Dunnett's multiple range tests. The results $p<0.05$ was used to indicate significance.

\section{Results and Discussion}

The selection of one from three sections; T-DVA, M-DVA and B-DVA

Generally, the DVA was divided into three segments, each of which is composed of different nutrients and biological compounds. Among the segments, T-DVA contained the highest amount of organic compounds. M-DVA contained equal amounts of both organic and inorganic compounds. B-DVA possessed the highest amount of inorganic compounds. However, which segments possess the highest inhibitory activity on prostate cancer cells is unclear.

Meanwhile, based on the report that many medical investigations and clinical observations showed that the disease-resistance ability was attributable to its antioxidant property (Dreher and Junod, 1996; Li et al., 2007; Waris and Ahsan, 2006). Valk et al. (2006) also insisted that antioxidant property played an important role in preventing diseases such as cancer, and coronary heart disease. Hence, the DPPH radical scavenging activity assay was used to evaluate the antioxidant activities of different segments. As shown in Fig. 1, the antioxidant activity of the T-DVA was significantly higher than those of M-DVA and B-DVA, and the corresponding trolox equivalent (TE) values were $53.44,40.33$, and $34.37 \mu \mathrm{M}$ at $1,000 \mu \mathrm{g} / \mathrm{mL}$, respectively. In addition, the result was same tendency as Kim et al. (2009a), and we assume this is from the highest amount of organic compounds in T-DVA. Consequently, T-DVA was examined the cytotoxicity on normal liver cells, THLE-2. Finally, we found that T-DVA had no cytotoxic effect on THLE-2 (data not shown). Hence, T-DVA was selected for the anti-prostate cancer experiment. Therefore, T-DVA was selected for the further experiments.

The effect of T-DVA on the expression of PSA in human prostate cancer cells

The expression of PSA was investigated using RT-PCR

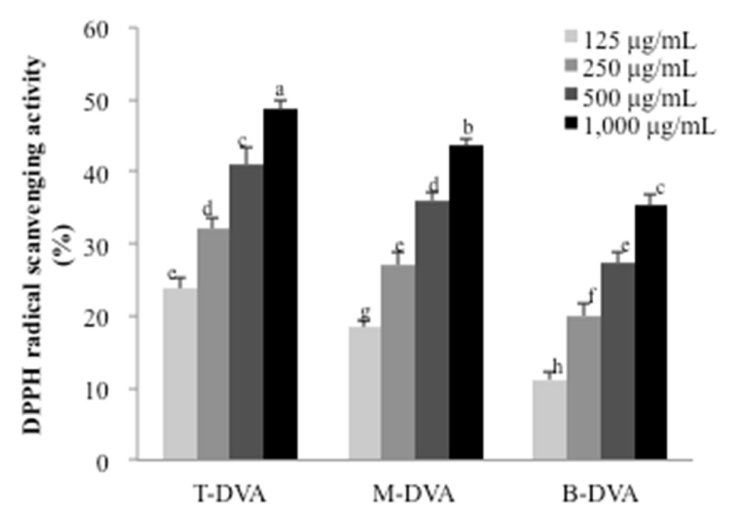

Fig. 1. The effect of DVA on DPPH radical scanvenging activity. ${ }^{\text {a-h }}$ Values with different superscriot are significantly different of $p<0.05$ as analyzed by Dunnertt's multiple range tests. 

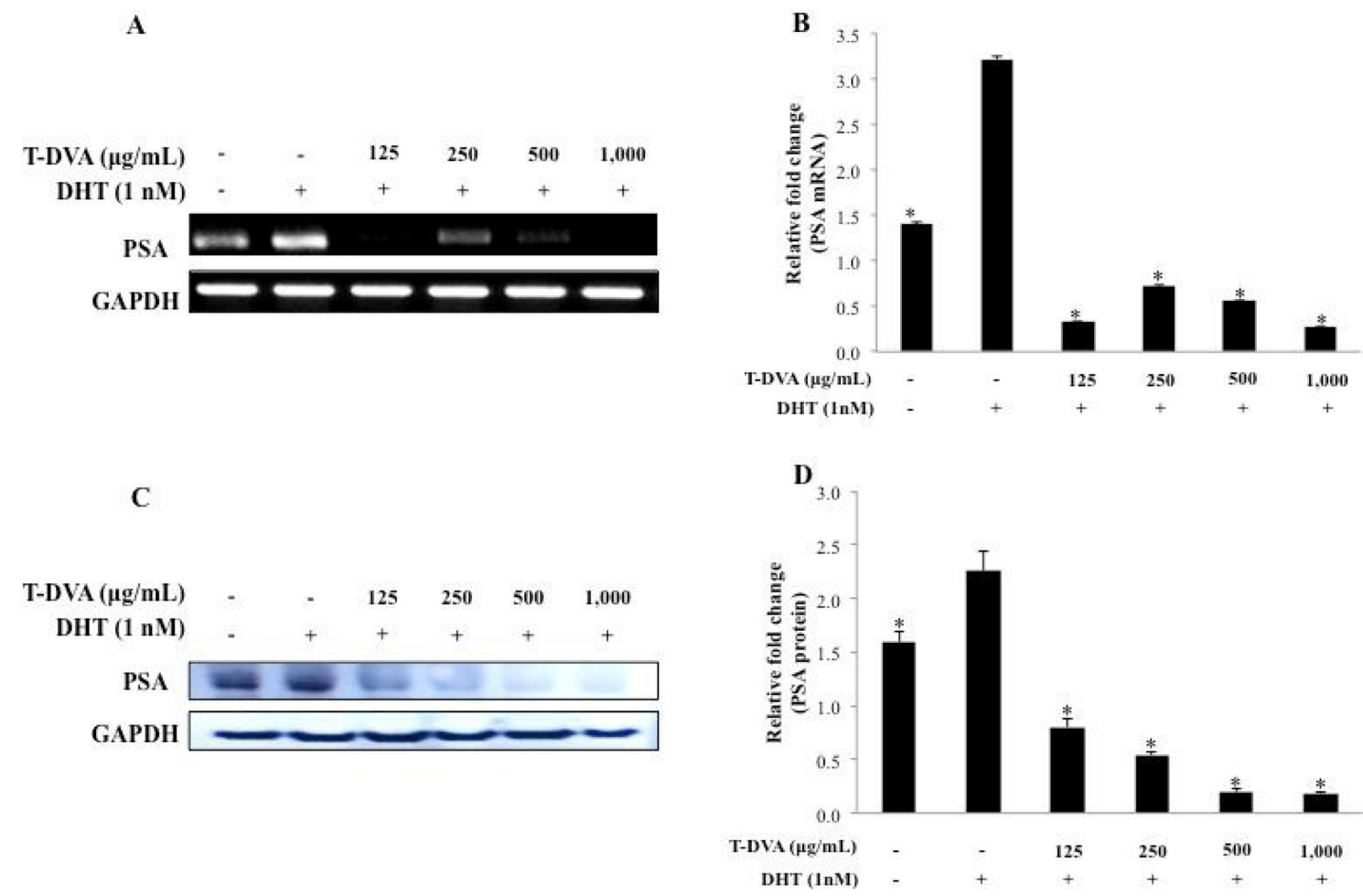

Fig. 2. The expression of PSA using RT-PCR and Western blot.mRNA (A, B) and protein (C, D) expression of PSA which were quantified by Image Guage (Fujifilm, Japan). Cells were treated with or without DHT and various concentrations of T-DVA for $24 \mathrm{~h}$. The mRNA and protein levels from whole cell lysates were analyzed by RT-PCR or Western blot, respectively. GAPDH and $\beta$-actin was used as a loading control. The results were similar in three independent experiments. *Significant difference from the DHT alone group shown at $p<0.05$.

after treatment with or without dihydrotestosterone (DHT, $0.1 \mathrm{nM}$ ) and T-DVA (125 to $1,000 \mu \mathrm{g} / \mathrm{mL}$ ) for $24 \mathrm{~h}$. DHT is a sex steroid and androgen hormone. DHT plays a role in the development and exacerbation of prostate cancer by enlarging the prostate gland. Therefore, prostate cancer growth is highly dependent on DHT (Freedland et al., 2005). PSA is a member of the kallikrein-related peptidase family and is secreted by the epithelial cells of the prostate gland. It is present in small quantities in the serum of men with healthy prostates, but its level is often elevated in cases of prostate cancer or other prostate disorders (Catalona et al., 1994). Hence, in current clinical practice, most oncologists monitor PSA levels more frequently (Burgio et al., 2014). Accordingly, we estimated the expression of PSA. In Fig. 2(A) and 2(B), treatment with DHT significantly increased PSA mRNA expression. However, the T-DVA significantly decreased PSA mRNA expression levels compared to DHT-alone group (Fig. 2(A), 2(B)). In addition, the protein expression of PSA was also estimated. As shown in Fig. 2(C) and 2(D), treatment with the T-DVA significantly suppressed the protein expression of PSA against DHT-alone treatment.

\section{The T-DVA inhibited the migratory behavior of human prostate cancer cells}

To examine the effect of the T-DVA on cell migration, we performed migration space closure assay using the Radius $^{\mathrm{TM}}$ 24-well. To compare the differences in migratory behavior, the images were printed at the same size, and the gap closure was determined after the indicated time ( 8 and $24 \mathrm{~h}$ ) compared to control. At $24 \mathrm{~h}$, the gap closed approximately $32.5 \%$ (DHT) and $8.53 \%$ (T-DVA $1,000 \mathrm{mg} / \mathrm{mL}$ ), respectively (Fig. 3). The result indicated that T-DVA possessed potent potential to suppress metastasis progress of prostate cancer cells.

Cell migration is an essential process in the development and maintenance of multicellular organisms (Ueno et al., 2004). Tissue formation during embryonic development, wound healing and immune responses require an orchestrated movement of cells in particular directions to specific locations (Yun et al., 2010). Errors during the process have serious consequences, including intellectual disability, vascular disease, tumor formation and metastasis (Guo et al., 2013). An understanding of the mechanism by which cells migrate may lead to the development 
A

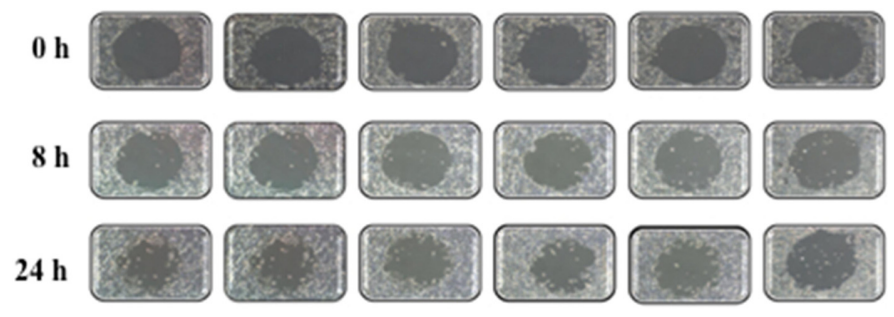

B

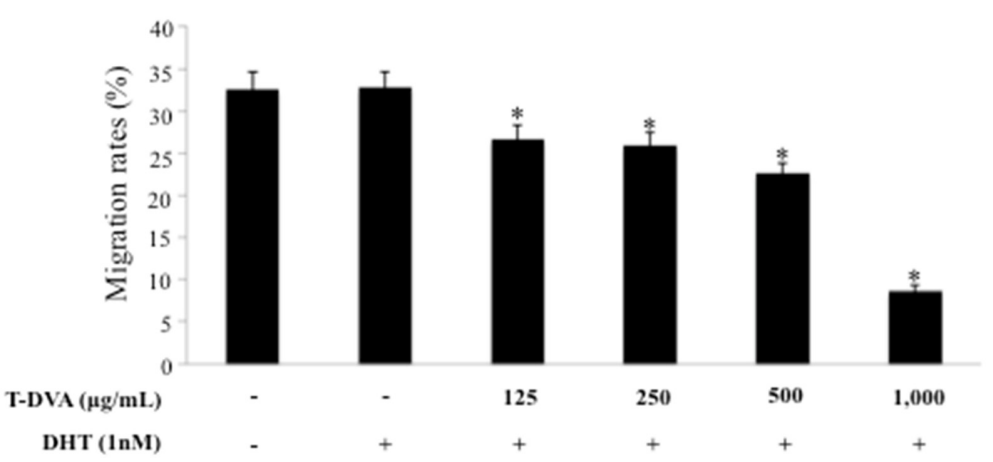

Fig. 3. Migration rates of T-DVA extract-treated LNCaP cells. A, Cell migration time course; B, images were captured at the same size, and gap closure was determined after the indicated times $(0,8,12$, and $24 \mathrm{~h})$ using CellProfiler ${ }^{\mathrm{TM}}$ software. Values not sharing a common letter are significantly different at $p<0.05$ by Dunnett's multiple range tests.

of novel therapeutic strategies for controlling, for example, invasive tumor cells.

\section{The effect of T-DVA on the expression of migration-} related genes in human prostate cancer cells

We also investigated the expression of migration-related genes. Initially, the mRNA expression levels of MMP-9, VEGF, TIMP-1, and TIMP-2 for 48h were estimated. As shown in (Fig. 4(A)-4(E)), treatment of LNCaP cells with the T-DVA significantly decreased the expression of MMP9 and VEGF in the DHT-treated T-DVA group. On the contrary, the expression of TIMP-1 and TIMP-2 was increased in the DHT-treated T-DVA group. For further identification, the protein expression of MMP-9, VEGF, TIMP-1 and TIMP-2 was also investigated by western blot (Fig. 4(F)-4(K)). T-DVA-treated groups showed a dose-dependent decrease in MMP-9 and VEGF levels; however, the levels of TIMP-1, and TIMP-2 increased in the T-DVAtreated groups.

MMP-9 can be involved in the development of several human malignancies, as degradation of collagen IV in the basement membrane and extracellular matrix facilitates tumor progression, including migration, metastasis, growth and angiogenesis (Guo et al., 2013). VEGF is a potent angiogenic factor and was first described as an essential growth factor for vascular endothelial cells (Itakura et al.,
2000). Not only is VEGF a major player in leukemias and lymphomas, it is also highly expressed in a variety of solid malignant tumors, and associated with progression of malignant diseases (Bellamy et al., 2001). Overexpression of VEGF in tumors is associated with increased angiogenesis, proliferation and metastasis. Meanwhile, TIMP-1 and TIMP-2 are tissue inhibitor of metalloproteinases (Jinga et al., 2006). They are critical to the maintenance of tissue homeostasis by suppressing the proliferation of quiescent tissues in response to angiogenic factors. They also inhibit protease activity in tissues undergoing remodeling of the extracellular matrix (Kamphorst et al., 2015).

\section{Conclusions}

DVA has been one of the most important medicines in Asia for more than 2000 years. In the present study, antimigration activities of DVA have been studied in prostate cancer cells. Firstly, the levels of the key marker of prostate cancer, PSA, were reduced. Furthermore, T-DVA inhibited the migration rate and expression of migration related-genes. It also increased the levels of TIMP-1 and TIMP2. This is the first study to report the anti-migration activity of DVA on prostate cancer cells. However, further work needs to be done to further elucidate the mechanism underlying DVA's anti-prostate cancer activity. 

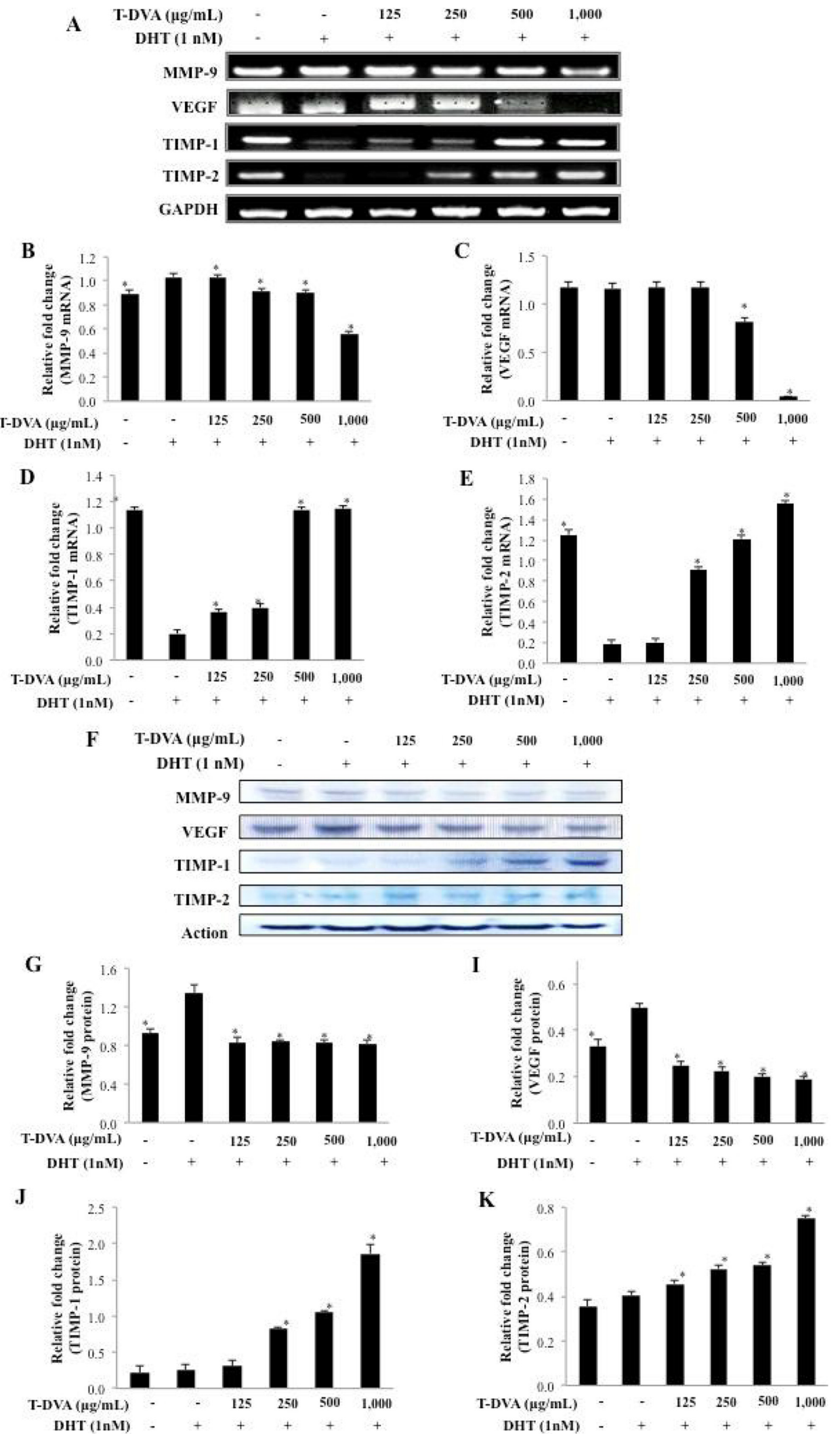

Fig. 4. The expression of migration-related genes using RT-PCR and Western blot.mRNA (A to E) and protein (F to K) expression of migration-related genes which were quantified by Image Guage (Fujifilm, Japan). Cells were treated with or without DHT and various concentrations of T-DVA for $24 \mathrm{~h}$. The mRNA and protein levels from whole cell lysates were analyzed by RTPCR or Western blot, respectively. GAPDH and $\beta$-actin was used as a loading control. The results were similar in three independent experiments. *Significant difference from the DHT alone group shown at $p<0.05$. 


\section{Acknowledgements}

This research was supported by Basic Science Research Program through the National Research Foundation of Korea (NRF) funded by the Ministry of Education, Science and Technology (2013R1A1A3006958) and by "Cooperative Research Program for Agriculture Science \& Technology Development (Project NO. P009773)" Rural Development Administration, Republic of Korea.

\section{References}

1. Bellamy, W. T., Richter, L., Sirjani, D., Roxas, C., GlinsmannGibson, B., Frutiger, Y., Grogan, T. M., and List, A. F. (2001) Vascular endothelial cell growth factor is an autocrine promoter of abnormal localized immature myeloid precursors and leukemia progenitor formation in myelodysplastic syndromes. Blood. 97, 1427-1434.

2. Blois, M. S. (1958) Antioxidant determinations by the use of a stable free radical. Nature 181, 1199-1200.

3. Burgio, S. L., Conteduca, V., Rudnas, B., Carrozza, F., Campadelli, E., Bianchi, E., Fabbri, P., Montanari, M., Carretta, Menna, C., and de Giorgi, U. (2015) PSA flare with abiraterone in patients with metastatic castration-resistant prostate cancer. Clin. Genitourin. Cancer 13, 39-43.

4. Catalona, W. J., Richie, J. P., Ahmann, F. R., Hudson, M. A., Scardino, P. T., Flanigan, R. C., Kernion, J. B., Ratliff, T. L., Kavoussi, L. R., and Dalkin, B. L. (1994) Comparison of digital rectal examination and serum prostate specific antigen in the early detection of prostate cancer: Results of a multicenter clinical trial of 6,630 men. J. Urol. 151, 1283-1290.

5. Cho, M., Hunt, T. K., and Hussain, M. Z. (2001) Hydrogen peroxide stimulates macrophage vascularendothelial growth factor release. Am. J. Phys. Heart Circ. Physiol. 280, H23572363.

6. Dreher, D. and Junod, A. F. (1996) Role of oxygen free radicals in cancer development. Eur. J. Cancer 32, 30-38.

7. Ferlay, J., Steliarova-Foucher, E., Lortet-Tieulent, J., Rosso, S., Coebergh, J. W., Comber, H., Forman, D., and Bray, F. (2013) Cancer incidence and mortality patterns in Europe: Estimates for 40 countries in 2012. Eur. J. Cancer 49, 13741403.

8. Freedland, S. J., Isaacs, W. B., Platz, E. A., Terris, M. K., Aronson, W. J., Amling, C. L., Presti, J. C., and Kane, C. J. (2005) Prostate size and risk of high-grade, advanced prostate cancer and biochemical progression after radical prostatectomy: a search database study. J. Clin. Oncol. 23, 7546-7554.

9. Guo, J., Li, L., Wu, Y. J., Yan, Y., Xu, X. N., Wang, S. B., Yuan, T. Y., Fang, L. H., and Du, G. H. (2013) Inhibitory effects of brazilin on the vascular smooth muscle cell proliferation and migration induced by PDGF-BB. Am. J. Chin. Med. 41, 12831296.

10. Itakura, J., Ishiwata, T., Shen, B., Kornmann, M., and Korc, M. (2000) Concomitant over-expression of vascular endothe- lial growth factor and its receptors in pancreatic cancer. Int. $J$. Cancer 85, 27-34.

11. Jinga, D. C., Blidaru, A., Condrea, I., Ardeleanu, C., Dragomir, C., Szegli, G., Stefanescu, M., and Matache, C. (2006) MMP-9 and MMP-2 gelatinases and TIMP-1 and TIMP-2 inhibitors in breast cancer: Correlations with prognostic factors. J. Cell Mol. Med. 10, 499-510.

12. Kamphors, E. B., Alexi, P., Tihaa, L., Haas, U., and Weiskirchen, R. (2015) Platelet-derived growthfactor-D modulates extracellular matrix homeostasis and remodeling through TIMP-1 induction and attenuation of MMP-2 and MMP-9 gelatinase activities. Biochem. Biophys. Res. Cотmи. Epub ahead of print (2015).

13. Kim, E. K., Lee, W. B., Moon, S. H., Jeon, Y. J., Ahn, C. B., Kim, B., Kim, B. H., Park, P. J., and Jeon, B. T. (2009a) Freeradical scavenging activity by ESR spectroscopy and neuroprotective effect on $\mathrm{H}_{2} \mathrm{O}_{2}$-induced damage in PC-12 cells of enzymatic exracts from Korean elk velvet antler. $J$. Food Biochem. 33, 895-912.

14. Kim, Y. D., Choi, S. C., Oh, T. Y., Chun, J. S., and Jun, C. D. (2009b) Eupatilin inhibits T-cell activationby modulation of intracellular calcium flux and NF-kappaB and NF-AT activity. J. Cell Biochem. 108, 225-236.

15. Li, Y. J., Kim, T. H., Kwak, H. B., Lee, Z. H., Lee, S. Y., and Jhon, G. J. (2007) Chloroform extract of deer antler inhibits osteoclast differentiation and bone resorption. J. Ethnopharmacol. 113, 191-198.

16. McCawlery, L. J. and Matrisian, L. M. (2001) Matrix metalloproteinases: They're not just for matrix anymore! Curr. Opin. Cell Biol. 13, 534-540.

17. Mehta, R. G. and Pezzuto, J. M. (2002) Discovery of cancer preventive agents from naturalproducts: From plants to prevention. Curr. Oncol. Rep. 4, 478-486.

18. Morgan, J., Rouche, A., Bausero, P., Houssaini, A., Gross, J., Fiszman, M. Y., and Alameddine, H. S. (2010) MMP-9 overexpression improves myogenic cell migration and engraftment. Muscle Nerve. 42, 584-595.

19. Nishimura, T., Nakamura, K., Kishioka, Y., Kato-Mori, Y., Wakamatsu, J., and Hattori, A. (2008) Inhibition of matrix metalloproteinases suppresses the migration of skeletal muscle cells. J. Muscle Res. Cell Motil. 29, 37-44.

20. Sunwoo, H. H., Nakano, T., and Sim, J. S. (1997) Effect of water-soluble extract from antler of wapiti (Cervus elaphus) on the growth of fibroblasts. Can. J. Animal Sci. 77, 343-345.

21. Takikawa, K., Kokubu, N., Kajihara, M., Doi, M., and Tahara, N. (1972) Experimental whiplashinjury. 3. Changes in enzyme activities of cervical cord and effect of Pantui extract pantocrin, pantocrin. Nihon Yakurigaku Zasshi. Folia Pharmacologica Japonica 68, 489-493.

22. Tormey, W. P. (2014) The complexity of PSA interpretation in clinical practice. J. Coll Surg. Edinb. 12, 323-327.

23. Ueno, T., Saito, F. D., Gray, H. D., Kuse, S., Hieshima, K., Nakano, H., Kakiuchi, T., Lipp, M., Boyd, R. L., and Takahama, Y. (2004) CCR7 signals are essential for Cortex-Medulla migration of developing thymocytes. J. Exp. Med. 200, 493505. 
24. Valko, M., Rhodes, C. J., Moncol, J., Izakovic, M., and Mazura, M. (2006) Free radicals, metals andantioxidants in oxidative stress-induced cancer. Chem. Biol. 160, 1-40.

25. Wang, B. X., Zhao, X. H., Yang, X. W., Kaneko, S., Hattori, M., Namba, T., and Nomura, Y. (1988) Inhibition of lipid peroxidation by deer antler (Rokujo) extract in vivo and in vitro, MedPharm Soc WAKAN-YAKU 5, 123-128.

26. Waris, G. and Ahsan, H. (2006) Reactive oxygen species: Role in the development of cancer andvarious chronic conditions. J. Carcinog. 10, 5-14.

27. Wu, F., Li, H., Jin, L., Li, X., Ma, Y., You, J., Li, S., and Xu, Y. (2013) Deer antler base as a traditional Chinese medicine:
A review of its traditional uses, chemistry and pharmacology. J. Ethnopharmacol. 145, 403-415.

28. Yun, Y. R., Won, J. E., Jeon, E., Lee, S., Kang, W., Jo, H., Jang, J. H., Shin, U. S., and Kim, H. W. (2010) Fibroblast growth factors: Biology, function, and application for tissue regeneration. J. Tissue Eng. 1, 18.

29. Zhang, Z. Q., Zhang, Y., Wang, B. X., Zhou, H. O., Wang, Y., and Zhang, H. (1992) Purification and partial haracterization of anti-inflammatory peptide from pilose antler of CervusnipponTemminck. Yao XueXueBao = Actapharmaceutica Sinica 27, 321 . 